Research Article

\title{
Fuzzy Comprehensive Evaluation of Happiness Index of Nine Cities in Pearl River Delta Based on AHP
}

\author{
Aili Xie $\mathbb{D}^{1},{ }^{1,2}$ Lianhua Liu $\mathbb{D}^{1,2}$ and Longyi Qin ${ }^{1}$ \\ ${ }^{1}$ Guangzhou Huashang College, GuangZhou 511300, Guangdong, China \\ ${ }^{2}$ Institute for Economic and Social Research, Huashang College, GuangZhou 511300, Guangdong, China \\ Correspondence should be addressed to Lianhua Liu; lianhua16@126.com
}

Received 26 July 2021; Accepted 7 September 2021; Published 20 September 2021

Academic Editor: Heng Liu

Copyright (C) 2021 Aili Xie et al. This is an open access article distributed under the Creative Commons Attribution License, which permits unrestricted use, distribution, and reproduction in any medium, provided the original work is properly cited.

\begin{abstract}
With the development of China's economy and the improvement of national income level, people's living demands have shifted from food and clothing to happiness, so happiness has become an important indicator to measure the performance of government performance. Scientific measure of residents' happiness is an important research topic for scholars, but the academic quantitative research on Chinese residents' happiness is less. A few quantitative studies often focus on the happiness of a single study subject at some time, and this paper uses the fuzzy comprehensive evaluation method to measure the nine cities in 2011-2018, not only the comparative happiness between horizontal cities and cities, and the study data longitudinal span from 2011 to 2018 . A comparative study of multiple objects across space-time was conducted. Empirical results show that the happiness level of urban residents in the Pearl River Delta has three characteristics: regional structure differentiation, urban group aggregation, and siphon effect in central cities, and the corresponding policy suggestions are put forward according to the results of the empirical research.
\end{abstract}

\section{Introduction}

"People's yearning for a better life is our goal." This is the pursuit of the Communist Party of China in the new era and the main requirement of General Secretary Xi Jinping's "People-centered development thought." The pursuit of the Communist Party of China is to make people live better and better, and "all the work of the Party is to seek happiness for the people." With the victory of the fight against poverty, residents' sense of happiness and security has become an important goal of social development. Happiness has become an important measure of the success of government governance. With the use of social science and natural science research methods in the field of happiness research, the results of empirical research on happiness are more and more, and the quantitative research of residents' happiness has become the focus of academic research.

The Pearl River Delta is located in the lower reaches of the Pearl River in Guangdong Province, adjacent to Hong Kong and Macao, and southeast Asia across the sea, land and sea traffic convenience, known as China's "South Gate." The
Pearl River Delta covers Guangzhou, Shenzhen, Foshan, Dongguan, Zhongshan, Zhuhai, Jiangmen, Zhaoqing, and Huizhou, a total of nine cities. According to the statistical data of the Guangdong Statistical Yearbook in 2019, there are 64.4689 million permanent residents in the region by 2019 , accounting for $55.96 \%$ of the permanent population of Guangdong Province, and the gross national product is 8689.905 billion yuan, accounting for $80.71 \%$ of the gross national product of Guangdong Province. The per capita income of residents reached 56638.7 yuan, and the per capita consumption expenditure reached 32862.44 yuan. The income level and consumption level of residents in the Pearl River Delta region are at the forefront in China. Exploring the differences and evolution of residents' happiness in nine cities in the Pearl River Delta has certain reference significance for improving national happiness. This paper will quantitatively study the evolution and development characteristics of happiness in nine cities in the Pearl River Delta through analytic hierarchy process and fuzzy comprehensive evaluation and put forward relevant development measures to improve residents' happiness. 


\section{Literature Review}

Happiness is a psychological experience of interaction between subjective and objective factors, involving psychology, sociology, economics, and other disciplines. Its influencing factors are mainly subjective and objective [1]. Scholars' research mainly focuses on the individual perspective and social perspective.

Happiness represents a positive emotion from an individual perspective, which is affected by the internal factors such as individual temperament, personality characteristics, and sense of goal $[2,3]$. Research focuses on the impact of gender, age, marriage, income, and social capital on happiness, such as women are happier than men [4]. Adolescents and the elderly have the highest happiness, and middle-aged have the lowest happiness [5]. Social capital support improves personal well-being $[6,7]$. However, there has always been disagreement in the academic circle about the impact of income on happiness. In 1974, Esterlin found that when a country or region's economy developed to a certain extent, residents' well-being would not continue to rise, or even fall, that is, the "Easterlin Paradox" [8]. "Relative income" has a greater impact on happiness than absolute income, and when income is higher than the average of the surrounding groups or regions, individuals will have stronger happiness [9]. International research on the happiness of Chinese residents mainly starts from the impact of online shopping [10], home debt hold [11, 12], consumer expenditure [13], property holding and investment $[14,15]$, and individual entrepreneurship [16]. The study found that online shopping can significantly improve the happiness of rural residents [10], family debt holdings have significantly reduced happiness $[11,12]$, consumer spending has a positive role on happiness [13], self-owned property improves happiness, but the rapid growth of property investment has a negative impact on happiness $[14,15]$, and entrepreneurship improves happiness by increasing family income [16].

From a social point of view, happiness factors include regional economic development, social security and environmental construction, and other macrosocial environmental factors [17]. Economic growth can improve residents' life satisfaction, happiness [18], and social stability. Economic development reduces disparities in wellbeing between and within countries [19]. However, economic policy uncertainty significantly reduces residents' happiness [20], risk prevention, and the pursuit of security which are people's instinctive needs. Compared with individual preventive measures, social security is a more reliable institutional guarantee. For example, unemployment insurance can effectively alleviate the insecurity of individuals with low economic status in the labor market [21]. Environment will affect residents' well-being [22-26]. Environmental economists have found that the environment can improve or reduce residents' well-being by stimulating residents' senses, such as air pollution is not conducive to human health, brings constant to residents' life, and reduces residents' well-being [27-29]. Studies in China found that CO change emissions significantly reduced residents' happiness [30], the disclosure of the mandatory air pollution index can boost happiness [31], but pollution emissions and environmental regulations do not necessarily improve happiness [32,33], the subjective concept of air pollution has a negative impact on residents' well-being [34], urbanization construction brings about perfect living infrastructure, accelerates the development of leisure tourism, and improves the happiness of residents, the construction of urban parks increases residents' happiness [35], and higher housing prices and wage growth from urbanization have a positive impact on happiness, but it also brings traffic congestion and smog to reduce residents' happiness [36].

In summary, the current research on happiness mainly focuses on the influencing factors of happiness but ignores the research on the differences in happiness among residents in different regions, including the distribution of happiness among residents in different regions, the existing differences, the characteristics of temporal and spatial evolution, and the influencing factors of regional happiness differences. This paper takes nine cities in the Pearl River Delta as the research object, analyzes the characteristics of residents' happiness difference, temporal and spatial evolution law, and influencing factors, and provides relevant development measures to improve residents' happiness.

\section{Research Methods and Data Sources}

3.1. Determining Weight by Analytic Hierarchy Process (AHP). Weight of each index is the key of fuzzy comprehensive evaluation. The analytic hierarchy process (AHP) is an effective method to determine the weight, which is suitable for solving the problem that it is difficult to completely quantitatively analyze. It can model and quantify the complex decision-making process, compare and calculate different indicators, and obtain the weight of different indicators. The steps of hierarchical analysis are as follows.

3.1.1. Building Hierarchical Structure Model. The analytic hierarchy process must first construct a hierarchical structure model to analyze the problem. In this model, complex problems are decomposed into components of different indicators, which form several levels according to their attributes and relationships. As Table 1 shows, this paper mainly sets up three levels of the index system, including the happiness of residents at the target level. The first-level index layer covers five index systems: residents' income level, residents' consumption level, residents' living environment, medical conditions, cultural environment, and 16 secondary index layers.

3.1.2. Constructing All Judgment Matrices at All Levels. The structural model reflects the relationship between different indicators, but the proportion of different indicators in the minds of decision makers is not the same. When determining the proportion of different indicators, some indicators are often difficult to quantify, especially when there are more indicators. Saaty et al. suggested that a pairwise comparison matrix could be established by pairwise 
TABLE 1: Evaluation index system of residents' happiness.

\begin{tabular}{|c|c|c|c|c|}
\hline Goal layer & First-level index & Second-level index & & \\
\hline \multirow{16}{*}{$\begin{array}{l}\text { Residents' } \\
\text { happiness }\end{array}$} & & Per capita GDP (¥) & $\mathrm{X} 11$ & \\
\hline & Residents income & Average wage of workers (¥) & $\mathrm{X} 12$ & A \\
\hline & \multirow{4}{*}{ Residents' consumption } & Per capita disposable income of urban residents (¥) & $\mathrm{X} 21$ & \\
\hline & & Per capita consumption expenditure of urban residents (¥) & $\mathrm{X} 22$ & B \\
\hline & & Per capita daily living water consumption (liter) & $\mathrm{X} 31$ & \\
\hline & & Per capita road area $\left(\mathrm{m}^{2}\right)$ & $\mathrm{X} 32$ & \\
\hline & \multirow{4}{*}{ Residents' living environment } & Sewage treatment rate $(\%)$ & $\mathrm{X} 33$ & $\mathrm{C}$ \\
\hline & & Per capita park green space area $\left(\mathrm{m}^{2}\right)$ & $\mathrm{X} 34$ & \\
\hline & & Garbage disposal rate $(\%)$ & X35 & \\
\hline & & Number of beds in hospitals and health centers (per 10000 person) & $\mathrm{X} 41$ & \\
\hline & \multirow[t]{2}{*}{ Residents' medical conditions } & $\begin{array}{c}\text { Number of people covered by urban basic medical insurance } \\
\text { (person) }\end{array}$ & $\mathrm{X} 42$ & $\mathrm{D}$ \\
\hline & & Primary school student-student ratio (\%) & $\mathrm{X} 51$ & \\
\hline & \multirow{4}{*}{$\begin{array}{c}\text { Cultural and educational } \\
\text { environment }\end{array}$} & $\begin{array}{l}\text { Ratio of teachers and students in secondary vocational education } \\
\qquad(\%)\end{array}$ & $\mathrm{X} 52$ & \\
\hline & & The ratio of normal high school students to teachers (\%) & $\mathrm{X} 53$ & \\
\hline & & The ratio of education expenditure to fiscal revenue (\%) & $\mathrm{X} 54$ & \\
\hline & & Public library $(\mathrm{s})$ & $\mathrm{X} 55$ & \\
\hline
\end{tabular}

comparison of indicators. All comparison results are obtained by matrix $S=\left(S_{\mathrm{ij}}\right)_{m \times n}$.

3.1.3. Calculation of Judgment Matrix. The maximum eigenvalue $\lambda_{\max }$ of judgment matrix $S$ and its corresponding eigenvector $W$ are calculated, and this eigenvector is the importance ranking of each evaluation index.

3.1.4. Consistency Check. When there are many evaluation indexes, the decision makers will put forward the data that are inconsistent with the actual importance due to poor consideration. Therefore, it is necessary to calculate the consistency index $\mathrm{CI}=\lambda_{\max }-n / n-1$. By searching the average random consistency index RI calculated by Saaty, the consistency ratio is calculated. When $\mathrm{CR}<0.1$, it is considered that the judgment matrix is consistent, and the weight distribution is basically reasonable. Otherwise, the judgment matrix should be reconstructed.

3.1.5. Determining Weight Vector $W$ of Evaluation Index. The weight vector is the relative value of the importance of the index. In this paper, the relative importance of each evaluation index is determined by AHP. According to the principle of AHP, the weight vector of each secondary index and the weight vector of the first index are obtained by MATLAB. When the fuzzy comprehensive evaluation is multilevel, the method of layer-by-layer evaluation is carried out. Firstly, the evaluation vector of each secondary index is obtained, and then the evaluation vector of the primary index is calculated. On the basis of AHP, according to the expert evaluation matrix, the weight value of the primary index is calculated: $W_{\mathrm{A}}, W_{\mathrm{B}}, W_{\mathrm{C}}, W_{\mathrm{D}}$, and $W_{\mathrm{E}}$.

3.2. Fuzzy Comprehensive Evaluation Method. The comprehensiveness of indicators should be considered in the comprehensive evaluation of things, involving multidimensional influencing factors. However, the multidimensional evaluation factors are not uncertain, but a vague concept. Fuzzy comprehensive evaluation method is suitable for multidimensional comprehensive evaluation of things. Fuzzy comprehensive evaluation transforms qualitative problems into quantitative problems through membership theory, which can well evaluate social phenomena that are difficult to quantify. The evaluation of residents' happiness involves many factors, such as social and economic development, social security, infrastructure construction, and social governance, and the above multidimensional factors need to be evaluated through a variety of indicators. Based on the comprehensiveness, scientificity, and availability of indicators, the comprehensive evaluation of residents' happiness is suitable for using the fuzzy comprehensive evaluation method.

3.3. Data Sources. The data of this study come from the statistical yearbooks of cities in the Pearl River Delta, China Urban Statistical Yearbook, China Urban Construction Statistical Yearbook, and China Urban and Rural Construction Statistical Yearbook. The data are selected from the statistical data of 2011-2018 and processed by MATLAB and Excel.

\section{Construction of Residents' Happiness Evaluation Index System}

Based on the research results of scholars, this paper adjusts the index system according to the principle of operable and finally forms five first-level indicators and 16 second-level indicators. The five first-level indicators are residents' income, residents' consumption, residents' living environment, residents' medical conditions, and cultural and educational environment. Second-level indicators are refined into per capita GDP, average wage of workers, per capita disposable income of urban residents, per capita living consumption expenditure of urban residents, per capita 
daily living water consumption, per capita road area, sewage treatment rate, per capita park green space area, garbage disposal rate, number of beds in hospitals and health centers, number of people covered by urban basic medical insurance, primary school student-student ratio, ratio of teachers and students in secondary vocational education, the ratio of normal high school students to teachers, the ratio of education expenditure to fiscal revenue, and public library, a total of 16 specific indicators in public libraries, as shown in Table 1.

\section{Fuzzy Comprehensive Evaluation of Happiness Index in Nine Cities of Pearl River Delta Based on AHP}

\subsection{Calculation of Index Weight}

\subsubsection{First-Level Index Weight Calculation}

(1) Establish a recursive hierarchy. First, the data are collected and organized by interviewing 21 experts, a total of 16 expert scoring comments are collected, and the requirements of the AHP law are met.

Second, according to Table 1, we will establish a priority system of happiness evaluation indicators in nine cities in the Pearl River Delta.

(2) Establish a pairwise comparison matrix.

First, set up the scaling of the judgment matrix, as shown in Table 2.

Second, according to the results of the expert questionnaire survey, data statistics were performed by the arithmetic averaging method to calculate the pairwise comparison judgment matrix in the standard layer in the evaluation index system, as shown in Table 3, and the judgment matrix is shown in the following formula:

$$
S=\left(\begin{array}{ccccc}
1 & 3 & 4 & 5 & 4 \\
\frac{1}{3} & 1 & 3 & 4 & 2 \\
\frac{1}{4} & \frac{1}{3} & 1 & 1 & \frac{1}{2} \\
\frac{1}{5} & \frac{1}{4} & 1 & 1 & \frac{1}{3} \\
\frac{1}{4} & \frac{1}{2} & 2 & 3 & 1
\end{array}\right)
$$

Determine the priority
TABLE 2: Usage of AHP as the significance comparison scale of each standard.

\begin{tabular}{lc}
\hline $\begin{array}{c}\text { Determine the scale and meaning of the matrix } \\
\text { Rcale value }\end{array}$ \\
$\begin{array}{lc}\text { Row and column trade-off } \\
\mathrm{Bij}=1 & \mathrm{Bi} \text { is slightly more important than } \mathrm{Bj} \\
\mathrm{Bij}=2 & \mathrm{Bi} \text { is significantly more important than } \mathrm{Bj} \\
\mathrm{Bij}=3 & \mathrm{Bi} \text { is much more important than } \mathrm{Bj} \\
\mathrm{Bij}=4 & \mathrm{Bi} \text { is definitely more important than } \mathrm{Bj} \\
\mathrm{Bij}=5 & \mathrm{Bi} \text { is slightly worse than } \mathrm{Bj} \\
\mathrm{Bij}=1 / 2 & \mathrm{Bi} \text { is significantly worse than } \mathrm{Bj} \\
\mathrm{Bij}=1 / 3 & \mathrm{Bi} \text { is much worse than } \mathrm{Bj} \\
\mathrm{Bij}=1 / 4 & \mathrm{Bi} \text { is absolutely worse than } \mathrm{Bj} \\
\mathrm{Bij}=1 / 5 & \end{array}$ \\
\hline
\end{tabular}

Using the statistical results of the previous pairwise judgment matrix, the priority level of each criterion was determined according to the evaluation criteria.

First, dividing each term in the pairwise comparison matrix by the sum of the columns yields the matrix as the standard pairwise comparison matrix.

Step 1 computes the sum of each column as shown in Table 4.

Step 2 divides each term of the matrix by the value of the sum of the columns that it contains, as shown in Table 5.

Second, the arithmetic average was calculated for each row in the standard pairwise comparison matrix. The arithmetic mean of each row is the priority of the evaluation criterion as the weight which is shown in Table 6.

\section{(4) Consistency test}

Key steps of the AHP method pay attention to the consistency of pairwise comparative judgments made by decision makers. The pairwise comparison in the AHP method is to calculate the consistency ratio. If the ratio is greater than 0.10 , which indicates an inconsistency in the pairwise comparison, if the consistency ratio is less than or equal to 0.10 , the pairwise comparison is more reasonable, and results can be judged using AHP and using metric priority as the weight of the scoring model.

The first step calculates the standard priority: multiply each $B_{1 j}$ of the first column in the pairwise matrix by the priority $X_{1}$ of the corresponding first standard, multiply each $B_{2 j}$ of the second column of the pairwise comparison matrix by the priority $X_{2}$ of the second standard, and then calculate the sum of each row to obtain a weighted vector value as calculated below: 
TABLe 3: Pairwise judgment matrix of first-level indicators.

\begin{tabular}{|c|c|c|c|c|c|}
\hline & $\begin{array}{l}\text { Residents' } \\
\text { income A }\end{array}$ & $\begin{array}{c}\text { Residents' } \\
\text { consumption B }\end{array}$ & $\begin{array}{l}\text { Residents' living } \\
\text { environment C }\end{array}$ & $\begin{array}{l}\text { Residents' medical } \\
\text { conditions D }\end{array}$ & $\begin{array}{c}\text { Cultural and educational } \\
\text { environment } \mathrm{E}\end{array}$ \\
\hline Residents' income A & 1 & 3 & 4 & 5 & 4 \\
\hline $\begin{array}{l}\text { Residents' consumption } \\
\text { B }\end{array}$ & $1 / 3$ & 1 & 3 & 4 & 2 \\
\hline $\begin{array}{l}\text { Residents' living } \\
\text { environment C }\end{array}$ & $1 / 4$ & $1 / 3$ & 1 & 1 & $1 / 2$ \\
\hline $\begin{array}{l}\text { Residents' medical } \\
\text { conditions D }\end{array}$ & $1 / 5$ & $1 / 4$ & 1 & 1 & $1 / 3$ \\
\hline $\begin{array}{l}\text { Cultural and educational } \\
\text { environment } \mathrm{E}\end{array}$ & $1 / 4$ & $1 / 2$ & 2 & 3 & 1 \\
\hline
\end{tabular}

TABLE 4: Summary of the pairwise judgment matrix.

\begin{tabular}{|c|c|c|c|c|c|}
\hline & $\begin{array}{l}\text { Residents' } \\
\text { income A } \\
\end{array}$ & $\begin{array}{c}\text { Residents' } \\
\text { consumption B } \\
\end{array}$ & $\begin{array}{l}\text { Residents' living } \\
\text { environment C }\end{array}$ & $\begin{array}{l}\text { Residents' medical } \\
\text { conditions D }\end{array}$ & $\begin{array}{c}\text { Cultural and educational } \\
\text { environment E }\end{array}$ \\
\hline Residents' income A & 1 & 3 & 4 & 5 & 4 \\
\hline $\begin{array}{l}\text { Residents' consumption } \\
\text { B }\end{array}$ & $1 / 3$ & 1 & 3 & 4 & 2 \\
\hline $\begin{array}{l}\text { Residents' living } \\
\text { environment C }\end{array}$ & $1 / 4$ & $1 / 3$ & 1 & 1 & $1 / 2$ \\
\hline $\begin{array}{l}\text { Residents' medical } \\
\text { conditions D }\end{array}$ & $1 / 5$ & $1 / 4$ & 1 & 1 & $1 / 3$ \\
\hline $\begin{array}{l}\text { Cultural and educational } \\
\text { environment } \mathrm{E}\end{array}$ & $1 / 4$ & $1 / 2$ & 2 & 3 & 1 \\
\hline Total & 2.033 & 5.083 & 11.000 & 14.000 & 7.833 \\
\hline
\end{tabular}

TABle 5: Pairwise judgment matrix normalization.

\begin{tabular}{lccccc}
\hline & $\begin{array}{c}\text { Residents' } \\
\text { income A }\end{array}$ & $\begin{array}{c}\text { Residents' } \\
\text { consumption B }\end{array}$ & $\begin{array}{c}\text { Residents' living } \\
\text { environment C }\end{array}$ & $\begin{array}{c}\text { Residents' medical } \\
\text { conditions D }\end{array}$ & $\begin{array}{c}\text { Cultural and educational } \\
\text { environment E }\end{array}$ \\
\hline $\begin{array}{l}\text { Residents' income A } \\
\text { Residents' consumption }\end{array}$ & 0.492 & 0.590 & 0.364 & 0.357 & 0.511 \\
$\begin{array}{l}\text { B } \\
\begin{array}{l}\text { Residents' living } \\
\text { environment C }\end{array}\end{array}$ & 0.164 & 0.197 & 0.273 & 0.286 & 0.255 \\
$\begin{array}{l}\text { Residents' medical } \\
\text { conditions D }\end{array}$ & 0.123 & 0.066 & 0.091 & 0.071 & 0.064 \\
$\begin{array}{l}\text { Cultural and educational } \\
\text { environment E }\end{array}$ & 0.123 & 0.049 & 0.091 & 0.071 & 0.043 \\
\hline
\end{tabular}

TABLE 6: Results of the primary index weight value.

\begin{tabular}{|c|c|c|c|c|c|c|}
\hline & $\begin{array}{l}\text { Residents' } \\
\text { income A }\end{array}$ & $\begin{array}{c}\text { Residents' } \\
\text { consumption B }\end{array}$ & $\begin{array}{l}\text { Residents' living } \\
\text { environment C }\end{array}$ & $\begin{array}{c}\text { Residents' } \\
\text { medical } \\
\text { conditions D } \\
\end{array}$ & $\begin{array}{c}\text { Cultural and } \\
\text { educational } \\
\text { environment E }\end{array}$ & $\begin{array}{c}\text { Weight } \\
\text { value }(\mathrm{W})\end{array}$ \\
\hline Residents' income A & 0.492 & 0.590 & 0.364 & 0.357 & 0.511 & 0.463 \\
\hline $\begin{array}{l}\text { Residents' } \\
\text { consumption B }\end{array}$ & 0.164 & 0.197 & 0.273 & 0.286 & 0.255 & 0.235 \\
\hline $\begin{array}{l}\text { Residents' living } \\
\text { environment C }\end{array}$ & 0.123 & 0.066 & 0.091 & 0.071 & 0.064 & 0.083 \\
\hline $\begin{array}{l}\text { Residents' medical } \\
\text { conditions D }\end{array}$ & 0.098 & 0.049 & 0.091 & 0.071 & 0.043 & 0.070 \\
\hline $\begin{array}{l}\text { Cultural and } \\
\text { educational } \\
\text { environmen } \mathrm{E}\end{array}$ & 0.123 & 0.098 & 0.182 & 0.214 & 0.128 & 0.149 \\
\hline
\end{tabular}


$\varnothing\left[\begin{array}{l}1 \\ \frac{1}{3} \\ \frac{1}{4} \\ \frac{1}{5} \\ \frac{1}{4}\end{array}\right]+0.235\left[\begin{array}{c}2 \\ 1 \\ \frac{1}{3} \\ \frac{1}{4} \\ \frac{1}{2}\end{array}\right]+0.083\left[\begin{array}{l}4 \\ 3 \\ 1 \\ 1 \\ 2\end{array}\right]+0.070\left[\begin{array}{l}5 \\ 1 \\ 1\end{array}\right]+0.149\left[\begin{array}{l}4 \\ \frac{1}{2} \\ 3\end{array}\right]$

$=\left[\begin{array}{l}0.463 \\ 0.154 \\ 0.116 \\ 0.093 \\ 0.116\end{array}\right]+\left[\begin{array}{l}0.705 \\ 0.235 \\ 0.078 \\ 0.059 \\ 0.117\end{array}\right]+\left[\begin{array}{l}0.332 \\ 0.249 \\ 0.083 \\ 0.083 \\ 0.166\end{array}\right]+\left[\begin{array}{l}0.352 \\ 0.282 \\ 0.070 \\ 0.070 \\ 0.211\end{array}\right]+\left[\begin{array}{l}0.596 \\ 0.298 \\ 0.075 \\ 0.050 \\ 0.149\end{array}\right]=\left[\begin{array}{l}2.448 \\ 1.218 \\ 0.422 \\ 0.354 \\ 0.759\end{array}\right]$.

The second step divides the weighted value obtained in the first step by the priority of the corresponding standard, as shown in the following calculation:

Resident income level (A) standard priority $=2.448$ / $0.463=5.290$

Resident consumption level (B) standard priority $=1.218 / 0.235=5.185$

Resident living environment (C) standard priority $=0.422 / 0.083=5.087$

Medical conditions (D) standard priority $=0.354$ / $0.070=5.027$

Cultural education environment (E) standard priority $=0.759 / 0.149=5.097$

The third step calculates the average of the standard priority:

$$
\lambda_{\max }=(5.290+5.185+5.087+5.027+5.097)=5.137 \text {. }
$$
follows:

The fourth step calculates the consistency ratio (CI) as

$$
\begin{aligned}
& \mathrm{CI}=\frac{\lambda_{\max }-n}{n-1}, \\
& \mathrm{CI}=\frac{5.137-5}{5-1}=0.034,
\end{aligned}
$$

where $n$ is the number of comparison items

The fifth step calculates the random consistency ratio. The definition is as follows:

$$
\mathrm{CR}=\frac{\mathrm{CI}}{\mathrm{RI}}
$$

where RI is a pairwise comparison matrix mean random consistency ratio whose size depends on the number of comparison terms, as shown in Table 7.

Calculating the maximum eigenvalue of judgment matrix $\lambda_{\max }=5.137$, to judge the consistency of matrices, the average random consistency index $\mathrm{RI}=1.12$ random consistency ratio is calculated:

$$
\mathrm{CR}=\frac{\mathrm{CI}}{\mathrm{RI}}=\frac{0.034}{1.12}=0.0303<0.10 .
$$

Therefore, it is believed that the results of AHP are consistent, and the weight distribution is also very reasonable. The corresponding feature vector is as follows: $\varphi=(2.448,1.218,0.422,0.354,0.759)$ and normalized weight matrix $W=(0.463,0.235,0.083,0.070,0.149)$.

5.1.2. Calculation of Second-Level Index Weight. The analytic hierarchy process is still used to calculate the weight of the second-level index. The judgment matrix of per capita GDP and average wage of employees under the primary index of residents' income level is given. Firstly, the maximum eigenvalue is calculated, and the consistency is verified. Then, the eigenvector is calculated, and the weight matrix is obtained by normalization:

$$
S_{A}=\left(\begin{array}{ll}
1 & \frac{1}{2} \\
2 & 1
\end{array}\right) .
$$

Calculating the maximum eigenvalue of judgment matrix $\lambda_{\max }=2.000, C I=\lambda_{\max }-n / n-1=0$. Therefore, the matrix is a consistency matrix, and the corresponding eigenvector is as follows: $\varphi=(0.667,1.333)$ and weight matrix $W_{A}=(0.333,0.667)$.

The judgment matrix is given for the per capita disposable income of urban residents and per capita living consumption expenditure of urban residents under the primary index of residents' consumption level. Firstly, the maximum eigenvalue is calculated for consistency verification, then the eigenvector is calculated, and the weight matrix is obtained through normalization processing (the calculation process is like the calculation step of primary index weight):

$$
S_{B}=\left(\begin{array}{cc}
1 & 3 \\
\frac{1}{3} & 1
\end{array}\right) .
$$

Calculating the maximum eigenvalue of judgment matrix $\lambda_{\max }=2.000, \quad \mathrm{CI}=\lambda_{\max }-n / n-1=0$. Therefore, the matrix is a consistency matrix, and the corresponding eigenvector is as follows: $\varphi=(1.500,0.500)$ and weight matrix $W_{B}=(0.750,0.250)$.

For the per capita daily water consumption of the secondary environment level index, per capita road area, sewage treatment rate, per capita park green area, and domestic waste treatment rate gives its judgment matrix, first calculate its maximum characteristic value consistency 
TABle 7: Pairwise mean random consistency ratio of the comparison matrix.

\begin{tabular}{lccccccccc}
\hline Dimension $(n)$ & 1 & 2 & 3 & 4 & 5 & 6 & 7 & 8 & 9 \\
\hline $\mathrm{RI}$ & 0 & 0 & 0.58 & 0.96 & 1.12 & 1.24 & 1.32 & 1.41 & 1.45 \\
\hline
\end{tabular}

verification, then calculate feature vector, and normalize the weight matrix (calculation steps of primary level index weight):

$$
S_{C}=\left(\begin{array}{ccccc}
1 & 2 & 3 & 4 & 5 \\
\frac{1}{2} & 1 & 3 & 3 & 4 \\
\frac{1}{3} & \frac{1}{3} & 1 & 2 & 3 \\
\frac{1}{4} & \frac{1}{3} & \frac{1}{2} & 1 & 2 \\
\frac{1}{5} & \frac{1}{4} & \frac{1}{3} & \frac{1}{2} & 1
\end{array}\right) .
$$

The maximum eigenvalue of the judgment matrix $\lambda_{\max }=5.121$ is calculated. In order to judge the consistency of the matrix, the average random consistency index $\mathrm{RI}=1.12$ random consistency ratio is calculated:

$$
\mathrm{CR}=\frac{\mathrm{CI}}{\mathrm{RI}}=\frac{0.030}{1.12}=0.027<0.10 \text {. }
$$

The corresponding feature vector is as follows: $\varphi=(2.120,1.475,0.760,0.492,0.313)$, normalized to obtain the weight matrix $W_{C}=(0.409,0.282,0.150,0.097,0.062)$.

For medical conditions under the secondary index of hospital and hospital beds and urban basic medical insurance ginseng gives its judgment matrix, first calculate the maximum feature value and consistency verification and then calculate the feature vector, through normalized processing weight matrix (calculation process such as primary index weight calculation steps):

$$
S_{D}=\left(\begin{array}{cc}
1 & \frac{1}{3} \\
& \\
3 & 1
\end{array}\right)
$$

The maximum eigenvalue of the judgment matrix is calculated as $\lambda_{\max }=2, \mathrm{CI}=\lambda_{\max }-n / n-1=0$, which is the consistency matrix. The corresponding feature vector is as follows: $\varphi=(0.500,1.500)$, and the weight matrix is obtained by normalization $W_{D}=(0.250,0.750)$.

The secondary index under the primary index of cultural education environment is as follows: primary school student ratio; secondary vocational education ratio; ordinary middle school student ratio; education expenditure to financial income; and the public library gives its judgment matrix, and first calculate its maximum feature value, conduct consistency verification, and then calculate the feature vector, normalized weight matrix (calculation process such as the calculation step of primary index weight):

$$
S_{E}=\left(\begin{array}{lllll}
1 & 1 & 1 & \frac{1}{2} & 1 \\
1 & 1 & 1 & \frac{1}{2} & 1 \\
1 & 1 & 1 & \frac{1}{2} & 1 \\
2 & 2 & 2 & 1 & 1 \\
1 & 1 & 1 & 1 & 1
\end{array}\right) .
$$

The maximum eigenvalue of the judgment matrix $\lambda_{\max }=5.058$ is calculated. In order to judge the consistency of the matrix, the average random consistency index $\mathrm{RI}=1.12$ random consistency ratio is calculated:

$$
\mathrm{CR}=\frac{\mathrm{CI}}{\mathrm{RI}}=\frac{0.015}{1.12}=0.013<0.10 .
$$

The corresponding feature vector is as follows: $\varphi=(0.851,0.8551,0.851,1.506,1.000)$, normalized to obtain the weight matrix $W_{E}=(0.169,0.169,0.169,0.169,0.297$, 0.197).

To sum up, the weight value of residents' well-being evaluation index system is obtained, as shown in Table 8.

\subsection{Fuzzy Comprehensive Evaluation Steps of Happiness Index of Nine Cities in Pearl River Delta}

5.2.1. Set of Evaluation Indicators for Determining Evaluation Objects. Evaluation of residents' happiness in 9 cities of the Pearl River Delta is as follows: $U=\left\{u_{1}, u_{2} \ldots u_{9}\right\}$.

\subsubsection{Establishment of Fuzzy Comprehensive Evaluation} Matrix for Secondary Index $R=\left(r_{i j}\right)_{m n}$. Due to the differences in dimension and quantity of indicators, the data are first standardized by standardized methods. The standardized processing formula is as follows:

$$
R_{m n}=\frac{r_{m n}-\min \left\{r_{m n}\right\}}{\max \left\{r_{m n}\right\}-\min \left\{r_{m n}\right\}} .
$$

The happiness evaluation index data of 9 cities are standardized, and the fuzzy evaluation matrix of secondary indexes is established according to each index. M is the secondary evaluation index of the happiness evaluation index system, and $n$ is the year. The $n$ year value of the $m$ index is expressed as $r_{n m}$. The standard value for the $n$ year of the $m$ index is expressed as $R_{\mathrm{mn}}$. The evaluation of the $m$ secondary factor is $\left(R_{\mathrm{m} 1}, R_{\mathrm{m} 2}, R_{\mathrm{m} 3}, R_{\mathrm{m} 4} \cdot R_{\mathrm{m} 5}, R_{\mathrm{m} 6}\right.$. $\left.R_{\mathrm{m} 7}, R_{\mathrm{m} 8}\right)$. Then, the corresponding fuzzy evaluation matrix of residents' happiness secondary indicators is as follows: 
TABLE 8: Weighting table of residents' happiness evaluation indicators.

\begin{tabular}{|c|c|c|c|c|c|}
\hline Goal layer & First-level index & $\begin{array}{l}\text { Weight value } \\
\qquad(W)\end{array}$ & Second-level index & Code & $\begin{array}{l}\text { Weight value } \\
\text { (W) }\end{array}$ \\
\hline \multirow{16}{*}{$\begin{array}{l}\text { Residents' } \\
\text { happiness }\end{array}$} & \multirow{2}{*}{ Residents' income (A) } & \multirow{2}{*}{0.463} & Per capita GDP $(¥)$ & $\mathrm{X} 11$ & 0.333 \\
\hline & & & Average wage of workers $(¥)$ & $\mathrm{X} 12$ & 0.667 \\
\hline & \multirow{2}{*}{ Residents' consumption (B) } & \multirow{2}{*}{0.235} & Per capita disposable income of urban residents & $\mathrm{X} 21$ & 0.750 \\
\hline & & & $\begin{array}{c}\text { Per capita consumption expenditure of urban } \\
\text { residents }(¥)\end{array}$ & $\mathrm{X} 22$ & 0.250 \\
\hline & \multirow{5}{*}{$\begin{array}{l}\text { Residents' living environment } \\
\text { (C) }\end{array}$} & \multirow{5}{*}{0.083} & Per capita daily living water consumption (liter) & X31 & 0.409 \\
\hline & & & Per capita road area $(\mathrm{m} 2)$ & $\mathrm{X} 32$ & 0.282 \\
\hline & & & Sewage treatment rate $(\%)$ & X33 & 0.150 \\
\hline & & & Per capita park green space area $(\mathrm{m} 2)$ & $\mathrm{X} 34$ & 0.097 \\
\hline & & & Garbage disposal rate (\%) & $\mathrm{X} 35$ & 0.062 \\
\hline & \multirow{2}{*}{$\begin{array}{l}\text { Residents' medical conditions } \\
\text { (D) }\end{array}$} & \multirow[b]{2}{*}{0.070} & $\begin{array}{l}\text { Number of beds in hospitals and health centers } \\
\text { (per } 10000 \text { person) }\end{array}$ & $\mathrm{X} 41$ & 0.250 \\
\hline & & & $\begin{array}{l}\text { Number of people covered by urban basic } \\
\text { medical insurance (person) }\end{array}$ & $\mathrm{X} 42$ & 0.750 \\
\hline & \multirow{5}{*}{$\begin{array}{l}\text { Cultural and educational } \\
\text { environment }(\mathrm{E})\end{array}$} & \multirow{5}{*}{0.149} & Primary school student-student ratio (\%) & $\mathrm{X} 51$ & 0.169 \\
\hline & & & $\begin{array}{c}\text { Ratio of teachers and students in secondary } \\
\text { vocational education (\%) }\end{array}$ & $\mathrm{X} 52$ & 0.169 \\
\hline & & & $\begin{array}{c}\text { The ratio of normal high school students to } \\
\text { teachers }(\%)\end{array}$ & $\mathrm{X} 53$ & 30.169 \\
\hline & & & $\begin{array}{c}\text { The ratio of education expenditure to fiscal } \\
\text { revenue (\%) }\end{array}$ & $\mathrm{X} 54$ & 0.297 \\
\hline & & & Public library $(\mathrm{s})$ & $\mathrm{X} 55$ & 0.197 \\
\hline
\end{tabular}

$$
R=\left[\begin{array}{cccccccc}
R_{11} & R_{12} & R_{13} & R_{14} & R_{15} & R_{16} & R_{17} & R_{18} \\
R_{21} & R_{22} & R_{23} & R_{24} & R_{25} & R_{26} & R_{27} & R_{28} \\
\vdots & \vdots & \vdots & \vdots & \vdots & \vdots & \vdots & \vdots \\
R_{m 1} & R_{m 2} & R_{m 3} & R_{m 4} & R_{m 5} & R_{m 6} & R_{m 7} & R_{m 8}
\end{array}\right]
$$

where $m=1,2, \ldots, 16, n=1,2, \ldots, 8$.

The fuzzy judgment matrix of 16 secondary indexes can be obtained according to formula (15) $\mathrm{R}_{\mathrm{Ai}}, \mathrm{R}_{\mathrm{Bj}}, \mathrm{R}_{\mathrm{Ck}}$, $\mathrm{R}_{\mathrm{Dl}}, \mathrm{R}_{\mathrm{Eh}}$.

As a result, the judgment vector $(\mathrm{V})$ is shown as follows:

$$
V=W \cdot R
$$

From formula (16), $\quad V_{A}^{(i)}=\mathrm{W}_{1 \mathrm{i}} \cdot \mathrm{R}_{\mathrm{Ai}}, \quad V_{B}^{(j)}=\mathrm{W}_{2 \mathrm{j}} \cdot \mathrm{R}_{\mathrm{Bj}}$, $V_{C}^{(k)}=\mathrm{W}_{3 \mathrm{k}} \cdot R_{\mathrm{C}}, V_{D}^{(l)}=\mathrm{W}_{4 \mathrm{l}} \cdot \mathrm{R}_{\mathrm{Dl}}, V_{E}^{(h)}=\mathrm{W}_{5 \mathrm{~h}} \cdot \mathrm{R}_{\mathrm{Eh}} \cdot \quad(i=1,2 ;$ $j=1,2 ; k=1,2, \ldots 5 ; l=1,2 ; h=1,2 . .5$ ).

5.2.3. Establishment of Fuzzy Comprehensive Evaluation Matrix for Primary Index. The fuzzy evaluation matrix $(R)$ of the main factors of the primary indicator is as follows:

$$
V=\left(V_{X}^{(1)}, V_{X}^{(2)} \ldots V_{X}^{(i)}\right)^{T}, \quad(X=A, B, C, D, E ; i=1,2 \ldots 5) .
$$

Form (17), it can be evolved into $R_{\mathrm{A}}=\left(V_{A}^{(1)}, V_{A}^{(2)}\right)^{\mathrm{T}}$; $R_{\mathrm{B}}=\left(V_{B}^{(1)}, V_{B}^{(2)}\right)^{\mathrm{T}} ; R_{\mathrm{C}}=\left(V_{C}^{(1)}, V_{C}^{(2)}, V_{C}^{(3)}, V_{C}^{(4)}, V_{C}^{(5)}\right)^{\mathrm{T}} ; R_{\mathrm{D}}=$ $\left(V_{D}^{(1)}, V_{D}^{(2)}\right)^{\mathrm{T}} ; R_{\mathrm{E}}=\left(V_{E}^{(1)}, V_{E}^{(2)}, V_{E}^{(3)}, V_{E}^{(4)}, V_{E}^{(5)}\right)^{\mathrm{T}}$.
5.2.4. Comprehensive Evaluation of Residents' Happiness Index. $U_{A}=\sum_{i=1}^{2} R A i, \quad U_{B}=\sum_{j=1}^{2} R B j, \quad U_{C}=\sum_{k=1}^{5} R C k$, $U_{D}=\sum_{l=1}^{2} R D l, U_{E}=\sum_{h=1}^{5} R E h$.

$U_{A}, U_{B}, U_{C}, U_{D}$, and $U_{E}$ are the membership degrees of the main factors $\mathrm{A}, \mathrm{B}, \mathrm{C}, \mathrm{D}$, and $\mathrm{E}$, respectively, and the weight vector is $W=\left(W_{A}, W_{B}, W_{C}, W_{D}, W_{E}\right)^{\mathrm{T}}$; then, the comprehensive evaluation of the happiness evaluation index is shown in equation (18). $D_{\mathrm{i}}$ is the comprehensive index of residents' happiness, $i=1,2,3, \ldots, 9$, representing nine cities in the Pearl River Delta:

$$
D_{i}=W \cdot U
$$

5.2.5. Residents' Happiness Index Comprehensive Evaluation Level. The range of membership degree value and $D$ value of residents' happiness index is [0-1]. According to $D$ value, the residents' happiness index is graded and evaluated, as shown in Table 9.

\section{Fuzzy Comprehensive Evaluation on Happiness Index of Nine Cities in Pearl River Delta}

6.1. Evolution Characteristics of Happiness of Nine Urban Residents in Pearl River Delta. According to calculation formulas (14)-(18), the primary index membership of the nine cities in the Pearl River Delta was calculated from 2011 to 2018, as shown in Tables 10-17.

Based on Tables 10-17, from the perspective of the primary index system, the evolution of happiness of residents in the Pearl River Delta has the following four 
TABLE 9: Evaluation grade of membership value $(U)$ and $D$ value.

\begin{tabular}{lc}
\hline Membership value $(U)$ and $(D)$ value & Evaluation level \\
\hline $0.8 \leq U / D<1.0$ & Excellent \\
$0.7 \leq U / D<0.8$ & Good \\
$0.5 \leq U / D<0.7$ & Middle \\
$0.3 \leq U / D<0.5$ & General \\
$0.0 \leq U / D<0.3$ & Unsatisfactory \\
\hline
\end{tabular}

Table 10: First-level membership of the happiness index of nine cities in the Pearl River Delta in 2011.

\begin{tabular}{lcccccc}
\hline 2011 & Membership $U_{A}$ & Membership $U_{B}$ & Membership $U_{C}$ & Membership $U_{D}$ & Membership $U_{E}$ & $\begin{array}{c}\text { Comprehensive membership } \\
\text { degree } D\end{array}$ \\
\hline Guangzhou & 0.89 & 0.81 & 0.40 & 0.62 & 0.54 & 0.75 \\
Shenzhen & 0.97 & 0.82 & 0.27 & 0.61 & 0.54 & 0.78 \\
Zhuhai & 0.61 & 0.48 & 0.56 & 0.27 & 0.30 & 0.50 \\
Zhongshan & 0.53 & 0.43 & 0.53 & 0.42 & 0.49 & 0.49 \\
Huizhou & 0.15 & 0.39 & 0.37 & 0.09 & 0.41 & 0.26 \\
Zhaoqing & 0.03 & 0.00 & 0.68 & 0.00 & 0.73 & 0.18 \\
Jiangmen & 0.06 & 0.23 & 0.26 & 0.20 & 0.70 & 0.22 \\
Dongguang & 0.45 & 0.99 & 0.44 & 0.95 & 0.31 & 0.58 \\
Foshan & 0.62 & 0.60 & 0.73 & 0.44 & 0.44 & 0.58 \\
\hline
\end{tabular}

Table 11: First-level membership of the happiness index of nine cities in the Pearl River Delta in 2012.

\begin{tabular}{lcccccc}
\hline 2012 & Membership $U_{A}$ & Membership $U_{B}$ & Membership $U_{C}$ & Membership $U_{D}$ & Membership $U_{E}$ & $\begin{array}{c}\text { Comprehensive membership } \\
\text { degree } D\end{array}$ \\
\hline Guangzhou & 0.87 & 0.81 & 0.49 & 0.25 & 0.45 & 0.71 \\
Shenzhen & 0.94 & 0.85 & 0.26 & 0.70 & 0.49 & 0.77 \\
Zhuhai & 0.59 & 0.53 & 0.84 & 0.38 & 0.30 & 0.53 \\
Zhongshan & 0.54 & 0.44 & 0.34 & 0.48 & 0.45 & 0.48 \\
Huizhou & 0.15 & 0.40 & 0.34 & 0.35 & 0.42 & 0.28 \\
Zhaoqing & 0.01 & 0.00 & 0.64 & 0.25 & 0.68 & 0.18 \\
Jiangmen & 0.04 & 0.23 & 0.37 & 0.32 & 0.55 & 0.21 \\
Dongguang & 0.41 & 1.00 & 0.56 & 0.94 & 0.31 & 0.58 \\
Foshan & 0.53 & 0.62 & 0.72 & 0.51 & 0.41 & 0.54 \\
\hline
\end{tabular}

Table 12: First-level membership of the happiness index of nine cities in the Pearl River Delta in 2013.

\begin{tabular}{lcccccc}
\hline 2013 & Membership $U_{A}$ & Membership $U_{B}$ & Membership $U_{C}$ & Membership $U_{D}$ & Membership $U_{E}$ & $\begin{array}{c}\text { Comprehensive membership } \\
\text { degree } D\end{array}$ \\
\hline Guangzhou & 0.56 & 0.85 & 0.59 & 0.50 & 0.55 & 0.62 \\
Shenzhen & 0.92 & 0.87 & 0.46 & 0.67 & 0.56 & 0.79 \\
Zhuhai & 0.35 & 0.55 & 0.74 & 0.27 & 0.37 & 0.42 \\
Zhongshan & 0.28 & 0.45 & 0.26 & 0.39 & 0.48 & 0.35 \\
Huizhou & 0.12 & 0.41 & 0.45 & 0.16 & 0.43 & 0.26 \\
Zhaoqing & 0.02 & 0.00 & 0.72 & 0.00 & 0.70 & 0.17 \\
Jiangmen & 0.02 & 0.24 & 0.43 & 0.15 & 0.65 & 0.21 \\
Dongguang & 0.40 & 1.00 & 0.57 & 0.90 & 0.21 & 0.55 \\
Foshan & 0.32 & 0.64 & 0.62 & 0.35 & 0.43 & 0.43 \\
\hline
\end{tabular}

characteristics: first, regional differences. The primary index of happiness of residents is in the same period, and there are regional differences between different cities. The second is structural difference. The first-level indicator system of residents' happiness is in the same city, and there are structural differences in different periods. Three is volatility change, and the Pearl River Delta urban residents' happiness development level index system exists volatility change. Four is the unbalanced development of indicators, the Pearl River Delta urban residents' wellbeing development level in the first-level index system of development imbalance. 
TABle 13: First-level membership of the happiness index of nine cities in the Pearl River Delta in 2014.

\begin{tabular}{lcccccc}
\hline 2014 & Membership $U_{A}$ & Membership $U_{B}$ & Membership $U_{C}$ & Membership $U_{D}$ & Membership $U_{E}$ & $\begin{array}{c}\text { Comprehensive membership } \\
\text { degree } D\end{array}$ \\
\hline Guangzhou & 0.89 & 0.81 & 0.40 & 0.62 & 0.54 & 0.75 \\
Shenzhen & 0.98 & 0.87 & 0.45 & 0.70 & 0.56 & 0.82 \\
Zhuhai & 0.64 & 0.64 & 0.69 & 0.27 & 0.37 & 0.57 \\
Zhongshan & 0.35 & 0.55 & 0.30 & 0.42 & 0.51 & 0.42 \\
Huizhou & 0.19 & 0.26 & 0.56 & 0.20 & 0.44 & 0.27 \\
Zhaoqing & 0.02 & 0.00 & 0.70 & 0.06 & 0.75 & 0.18 \\
Jiangmen & 0.01 & 0.14 & 0.43 & 0.12 & 0.60 & 0.17 \\
Dongguang & 0.16 & 0.69 & 0.61 & 0.86 & 0.19 & 0.37 \\
Foshan & 0.46 & 0.67 & 0.52 & 0.38 & 0.41 & 0.50 \\
\hline
\end{tabular}

TAвLE 14: First-level membership of the happiness index of nine cities in the Pearl River Delta in 2015.

\begin{tabular}{lcccccc}
\hline 2015 & Membership $U_{A}$ & Membership $U_{B}$ & Membership $U_{C}$ & Membership $U_{D}$ & Membership $U_{E}$ & $\begin{array}{c}\text { Comprehensive membership } \\
\text { degree } D\end{array}$ \\
\hline Guangzhou & 0.87 & 1.00 & 0.50 & 0.54 & 0.58 & 0.79 \\
Shenzhen & 1.00 & 0.89 & 0.39 & 0.66 & 0.56 & 0.82 \\
Zhuhai & 0.64 & 0.64 & 0.69 & 0.29 & 0.29 & 0.56 \\
Zhongshan & 0.34 & 0.54 & 0.31 & 0.39 & 0.47 & 0.41 \\
Huizhou & 0.17 & 0.27 & 0.46 & 0.18 & 0.44 & 0.26 \\
Zhaoqing & 0.01 & 0.00 & 0.50 & 0.00 & 0.76 & 0.16 \\
Jiangmen & 0.02 & 0.14 & 0.44 & 0.09 & 0.60 & 0.17 \\
Dongguang & 0.17 & 0.69 & 0.55 & 0.89 & 0.18 & 0.37 \\
Foshan & 0.47 & 0.68 & 0.64 & 0.40 & 0.48 & 0.52 \\
\hline
\end{tabular}

TABLE 15: First-level membership of the happiness index of nine cities in the Pearl River Delta in 2016.

\begin{tabular}{lcccccc}
\hline 2016 & Membership $U_{A}$ & Membership $U_{B}$ & Membership $U_{C}$ & Membership $U_{D}$ & Membership $U_{E}$ & $\begin{array}{c}\text { Comprehensive membership } \\
\text { degree } D\end{array}$ \\
\hline Guangzhou & 0.85 & 1.00 & 0.45 & 0.57 & 0.57 & 0.78 \\
Shenzhen & 1.00 & 0.91 & 0.25 & 0.73 & 0.59 & 0.83 \\
Zhuhai & 0.66 & 0.67 & 0.61 & 0.29 & 0.28 & 0.57 \\
Zhongshan & 0.35 & 0.59 & 0.40 & 0.40 & 0.46 & 0.43 \\
Huizhou & 0.19 & 0.29 & 0.42 & 0.17 & 0.40 & 0.26 \\
Zhaoqing & 0.02 & 0.00 & 0.40 & 0.00 & 0.70 & 0.15 \\
Jiangmen & 0.05 & 0.14 & 0.26 & 0.09 & 0.32 & 0.13 \\
Dongguang & 0.18 & 0.67 & 0.41 & 0.87 & 0.23 & 0.37 \\
Foshan & 0.47 & 0.68 & 0.66 & 0.41 & 0.43 & 0.52 \\
\hline
\end{tabular}

Table 16: First-level membership of the happiness index of nine cities in the Pearl River Delta in 2017.

\begin{tabular}{lcccccc}
\hline 2017 & Membership $U_{A}$ & Membership $U_{B}$ & Membership $U_{C}$ & Membership $U_{D}$ & Membership $U_{E}$ & $\begin{array}{c}\text { Comprehensive membership } \\
\text { degree } D\end{array}$ \\
\hline Guangzhou & 0.82 & 1.00 & 0.48 & 0.57 & 0.56 & 0.77 \\
Shenzhen & 1.00 & 0.91 & 0.22 & 0.68 & 0.56 & 0.82 \\
Zhuhai & 0.69 & 0.69 & 0.33 & 0.31 & 0.27 & 0.57 \\
Zhongshan & 0.33 & 0.60 & 0.51 & 0.44 & 0.38 & 0.42 \\
Huizhou & 0.23 & 0.32 & 0.41 & 0.11 & 0.29 & 0.26 \\
Zhaoqing & 0.03 & 0.00 & 0.49 & 0.00 & 0.66 & 0.15 \\
Jiangmen & 0.08 & 0.16 & 0.36 & 0.11 & 0.42 & 0.17 \\
Dongguang & 0.20 & 0.67 & 0.55 & 0.87 & 0.12 & 0.37 \\
Foshan & 0.46 & 0.68 & 0.71 & 0.39 & 0.40 & 0.51 \\
\hline
\end{tabular}

6.1.1. Regional Difference. The first-level index of happiness development level of urban residents in the Pearl River Delta has regional development differences in the same period.
The dimension of each index is different. In order to standardize the data, this paper first standardizes the data. After fuzzy comprehensive evaluation, the results show 
Table 17: First-level membership of the happiness index of nine cities in the Pearl River Delta in 2018.

\begin{tabular}{lcccccc}
\hline 2018 & Membership $U_{A}$ & Membership $U_{B}$ & Membership $U_{C}$ & Membership $U_{D}$ & Membership $U_{E}$ & $\begin{array}{c}\text { Comprehensive membership } \\
\text { degree } D\end{array}$ \\
\hline Guangzhou & 0.83 & 1.00 & 0.75 & 0.62 & 0.62 & 0.81 \\
Shenzhen & 1.00 & 0.92 & 0.16 & 0.74 & 0.57 & 0.82 \\
Zhuhai & 0.66 & 0.70 & 0.76 & 0.32 & 0.30 & 0.59 \\
Zhongshan & 0.32 & 0.60 & 0.67 & 0.48 & 0.39 & 0.43 \\
Huizhou & 0.22 & 0.32 & 0.41 & 0.11 & 0.28 & 0.26 \\
Zhaoqing & 0.01 & 0.00 & 0.70 & 0.00 & 0.66 & 0.16 \\
Jiangmen & 0.06 & 0.16 & 0.59 & 0.11 & 0.47 & 0.19 \\
Dongguang & 0.22 & 0.67 & 0.57 & 0.86 & 0.16 & 0.39 \\
Foshan & 0.45 & 0.68 & 0.72 & 0.42 & 0.43 & 0.51
\end{tabular}

different cities in the same period and the same evaluation index, and the membership value is different. It shows different cities in the same period, under the same evaluation index, and there are regional differences in the development level of residents' happiness level evaluation index. As shown in Figure 1, taking the membership degree of residents' income level $U_{A}$ in 2011 as an example, Zhaoqing had the lowest $U_{A}$ membership degree in 2011, and its $U_{A}$ membership degree value was 0.03 . Shenzhen had the highest $U_{A}$ membership degree, and its $U_{A}$ membership degree value was 0.97 . The range was 0.94 . The range value was great, indicating that the regional difference of residents' income was very obvious. Next is Guangzhou, its $U_{A}$ membership value is 0.89 , and Shenzhen and Guangzhou evaluation grade is excellent. Foshan, Zhuhai, and Zhongshan membership evaluation level is medium, Foshan ranked third, and its $U_{A}$ membership value was $0.62,0.27$ smaller than that of Guangzhou ranked second. Zhuhai was very close to Foshan, and its $U_{A}$ membership value was 0.61 . Zhongshan ranked fifth, and its $U_{A}$ membership value was 0.53 . Dongguan ranks sixth, its $U_{A}$ membership value is 0.45 , and the evaluation level is general. The $U_{A}$ membership of Huizhou is 0.15 , the $U_{A}$ membership of Jiangmen is 0.06 , and the $U_{A}$ evaluation grade of Huizhou, Jiangmen, and Zhaoqing is poor. Similarly, $U_{B}, U_{C}, U_{D}$, and $U_{E}$ also have the phenomenon of unbalanced regional development in the same period. In summary, in the same period, the Pearl River Delta urban residents' happiness development level evaluation index is as follows: residents' income level, residents' consumption level, residents' living environment, medical conditions, and cultural and educational environment development exist significant regional differences.

6.1.2. Structural Difference. The primary index system of happiness development level of urban residents in the Pearl River Delta has structural differences in different periods of the same city. This paper selects the membership value of the first-level index system of happiness of residents in Guangzhou in 2011, 2015, and 2018, as shown in Figure 2. The happiness index of Guangzhou residents in 2011 was $0.75,2015$ was 0.79 , and 2018 was 0.81 , and the happiness index value changed little, indicating that the comprehensive index of happiness of residents in the Pearl River Delta remained stable in nine cities. However, the internal structure of the first-level evaluation index has certain temporal structure difference, which is reflected in the combination structure change of its membership value. When the weight value $W$ remains unchanged, the size and composition of the $U$ value determine the size of the residents' happiness index $D$ value. In 2011, the $D$ value of the happiness index of Guangzhou residents was 0.75 , and the membership structure of $U$ was as follows: $U_{A}, U_{B}, U_{C}, U_{D}$, and $U_{E}$ were $0.89,0.81,0.4,0.62$, and 0.54 , respectively. Compared with 2011, the $D$ value increment of residents' well-being index in Guangzhou in 2015 was 0.2, with $U_{A}$ decrement of $0.04, U_{B}$ increment of $0.19, U_{C}$ increment of $0.1, U_{D}$ decrement of 0.08 , and $U_{E}$ increment of 0.04 . Compared with 2015, the $D$ value of Guangzhou residents' happiness index in 2018 increased by 0.2 , the $U_{A}$ reduction was 0.04 , the $U_{B}$ was 1 , the $U_{C}$ increment was 0.25 , the $U_{D}$ increment was 0.08 , and the $U_{E}$ increment was 0.04 . It can be seen that the first-level index system of urban residents in the Pearl River Delta has structural differences in different periods of the same city.

6.1.3. Fluctuation Variability. The first-level index system of happiness development level of urban residents in the Pearl River Delta is fluctuating. Taking Dongguan City as an example, among the first-level indicators, Dongguan has the largest fluctuation. The residents' income membership in Dongguan has declined from $0.45,0.4$, and 0.40 in 2011, 2012, and 2013 to 0.16 in 2014 year by year, and then slowly increased, but it has been hovering at a low level until 2018, and its membership reached 0.22 , far lower than that of Foshan, Zhongshan, and Zhuhai. The membership of residents' consumption fell from $0.99,1.00$, and 1.00 in 2011, 2012, and 2013 to 0.69 in 2014 and has been hovering in this position. The sharp decline in these two indicators has affected the comprehensive ranking of Dongguan in the nine cities of the Pearl River Delta.

6.1.4. Unbalanced Development of Indicators. There is a development imbalance between the first-level index system of happiness development level of urban residents in the Pearl River Delta. Taking Shenzhen as an example, as shown in Tables 9-16, the residents' income membership is 0.97 in 2011, 1 in 2015, and 1 in 2018, which reflects that the residents' income level ranks first in the cities of the Pearl River Delta. However, the residents' consumption expenditure 


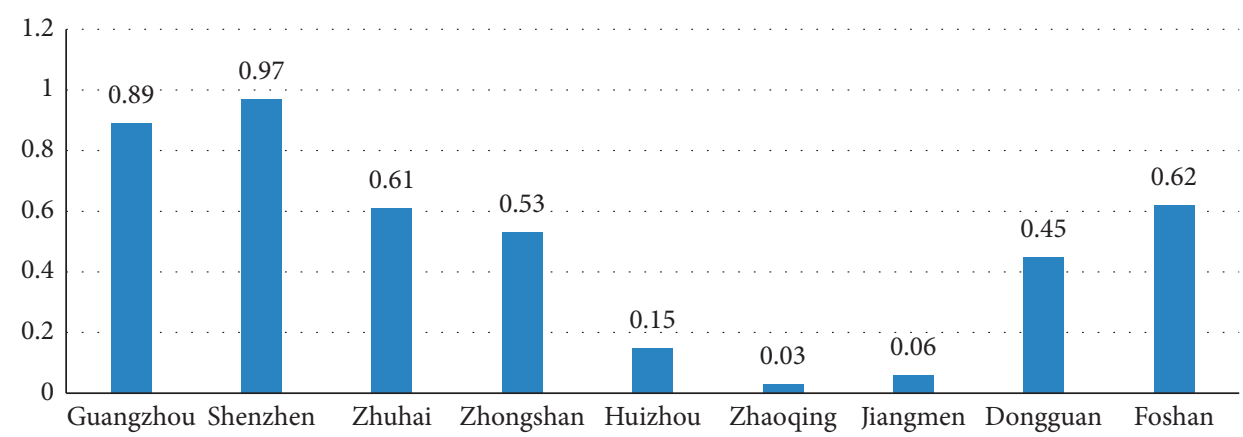

FIgURE 1: Regional difference map of $U_{\mathrm{A}}$ value in 2011.
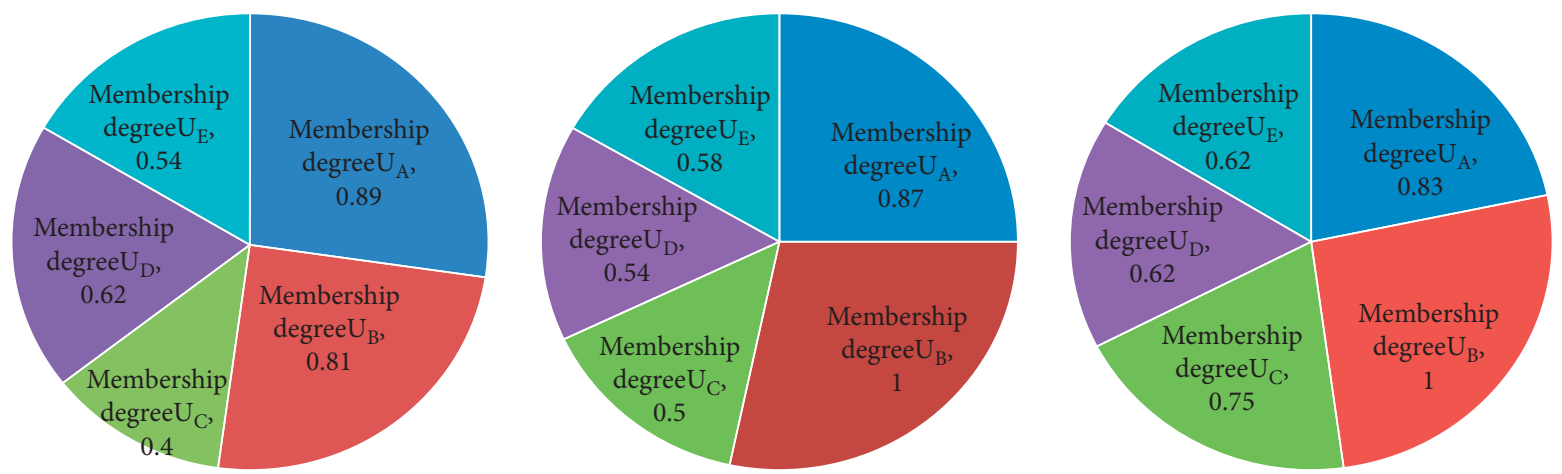

Figure 2: Evolution of the composite structure of the membership degree of the primary index of the happiness index of Guangzhou residents.

membership in the primary index system is 0.82 in $2011,0.89$ in 2015 , and 0.92 in 2018 . At the same time, the data in the primary index system show that the development level of residents' income in Shenzhen is far faster than that of residents' consumption expenditure. The living environment membership of Shenzhen residents is 0.27 in 2011, 0.39 in 2015, and 0.16 in 2018, which does not match the ranking of residents' income and residents' consumption expenditure in the Pearl River Delta, reflecting the unbalanced development of the first-level index system.

6.2. Comparative Analysis of Comprehensive Happiness Evaluation Indexes of Nine Urban Residents in Pearl River Delta. According to equation (18), the comprehensive happiness evaluation index of nine cities from 2011 to 2018 can be obtained, as shown in Table 18 .

6.2.1. Regional Difference and Development Change of Residents' Happiness Level in Nine Cities of Pearl River Delta. The resident happiness index is different in the Pearl River Delta cities. As shown in Figure 3, it reflects the imbalance of the comprehensive development level of the happiness index in different cities of the Pearl River Delta.

Residents' happiness index shows a trend of development and change, but the ranki is relatively stable, the evaluation grade is general, Huizhou, Zhaoqing, and Jiangmen evaluation grade is poor, and ranking tends to be stable, basically in low wandering.
Development tends to be stable. As shown in Figure 4, Shenzhen and Guangzhou have been at the top of the list, the comprehensive index of residents' happiness has increased year by year, and its evaluation level has been above good. Followed by Foshan, Zhuhai evaluation level has been medium. The volatility of Dongguan is relatively large, and the turning point of its development in 2013 is mainly due to the negative impact of the sharp decline of $U_{A}$ membership value, reflecting the pain of residents' happiness caused by the decline of residents' income level caused by the change of growth mode in Dongguan. The comprehensive happiness index of residents is relatively stable in Zhongshan which is general. The comprehensive happiness index of residents is poor, and the ranking tends to be stable at a low level in Huizhou, Zhaoqing, and Jiangmen.

\subsubsection{The Comprehensive Happiness Index of Residents in} Nine Cities of Pearl River Delta Has Urban Group Characteristics. The comprehensive happiness index of residents in the nine cities of the Pearl River Delta has the characteristics of urban groups, and there is a high value of the local happiness index in urban agglomerations and overflows to the low value areas. With the integrated development of Guangdong-Hong Kong-Macao Greater Bay Area and the further integration of economy, transportation, and culture, the comprehensive well-being index of residents in the nine cities of the Pearl River Delta shows the characteristics of groupization and gradually forms a group of three major cities in the east, middle, and west. The east 
TABle 18: Comprehensive well-being evaluation index of cities 2011-2018.

\begin{tabular}{lccccccc}
\hline & 2011 & 2012 & 2013 & 2014 & 2015 & 2016 & 2017 \\
\hline Guangzhou & 0.75 & 0.71 & 0.62 & 0.75 & 0.79 & 0.78 & 0.77 \\
Shenzhen & 0.78 & 0.77 & 0.79 & 0.82 & 0.82 & 0.83 & 0.82 \\
Zhuhai & 0.50 & 0.53 & 0.42 & 0.57 & 0.56 & 0.57 & 0.81 \\
Zhongshan & 0.49 & 0.48 & 0.35 & 0.42 & 0.41 & 0.43 & 0.82 \\
Huizhou & 0.26 & 0.28 & 0.26 & 0.27 & 0.26 & 0.26 & 0.26 \\
Zhaoqing & 0.18 & 0.18 & 0.17 & 0.18 & 0.16 & 0.15 & 0.15 \\
Jiangmen & 0.22 & 0.21 & 0.21 & 0.17 & 0.17 & 0.13 & 0.17 \\
Dongguang & 0.58 & 0.58 & 0.55 & 0.37 & 0.37 & 0.37 & 0.16 \\
Foshan & 0.58 & 0.54 & 0.43 & 0.50 & 0.52 & 0.52 & 0.19 \\
\hline
\end{tabular}

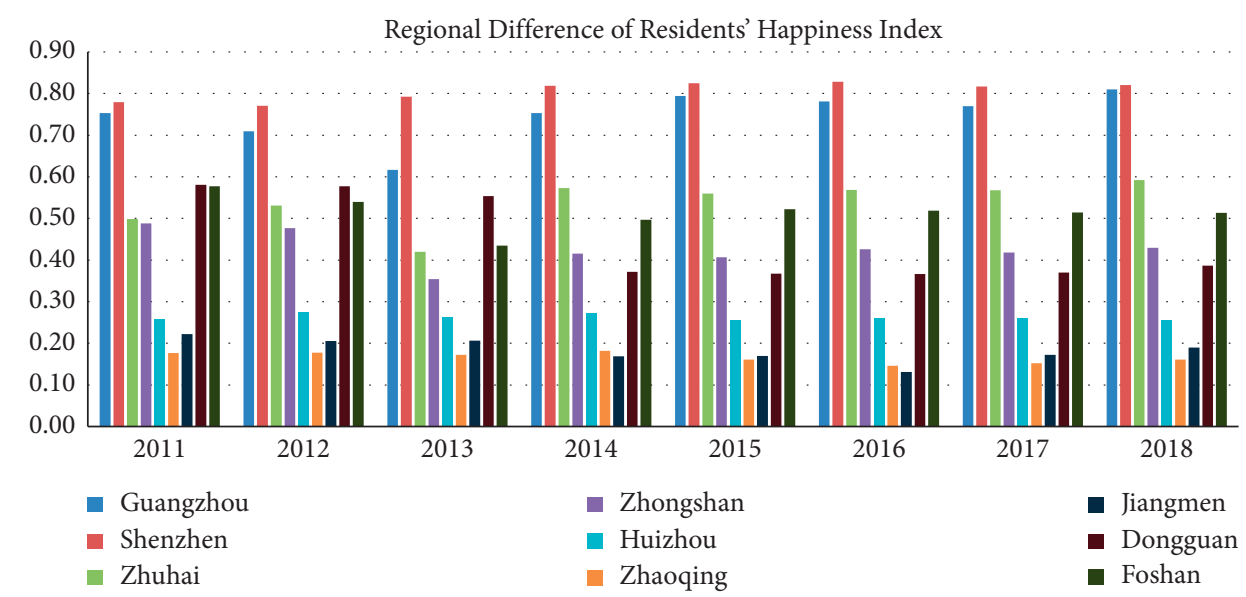

Figure 3: Regional differentiation of the happiness comprehensive index of the Pearl River Delta residents.

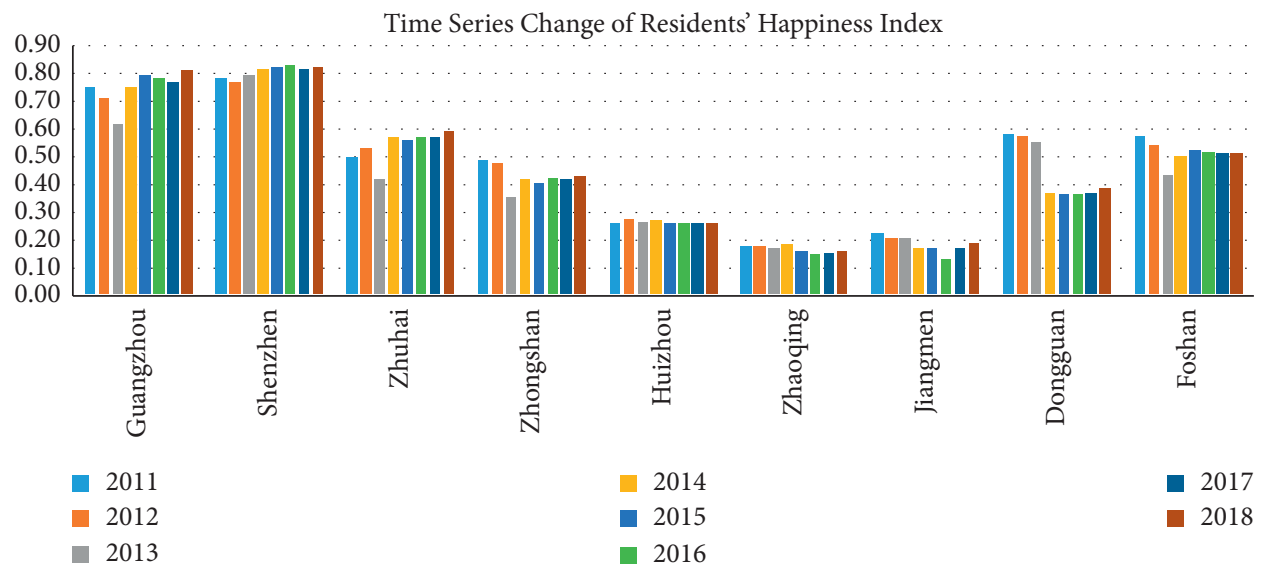

FIgURE 4: Time series changes of the comprehensive happiness index of residents in the Pearl River Delta.

includes Shenzhen, Dongguan, and Huizhou, the middle includes Guangzhou, Foshan, and Zhaoqing, and the west includes Zhuhai, Zhongshan, and Jiangmen. According to the data, each urban group shows a local happiness index highland and overflows to the surrounding cities. The three major cities in the east, middle, and west are centered on Shenzhen, Guangzhou, and Zhuhai, and centered on these three cities, radiating the surrounding cities, reflecting the integrated development of Guangdong-Hong Kong-Macao Greater Bay Area.
6.2.3. The Happiness Level of Residents in Nine Cities of Pearl River Delta Has a Certain Siphon Effect. The comprehensive happiness index of residents in the nine cities of the Pearl River Delta shows a certain siphon effect. The happiness index of Shenzhen, Guangzhou, and Zhuhai, the three central cities in the east, middle, and west of the Pearl River Delta, is increasing year by year. The index of the other six cities is decreasing year by year. The gap between the happiness index of the central city and the surrounding cities is increasing year by year. Because of its economic 
advantages, capital advantages, and industrial advantages, the central city has siphon effect on the surrounding cities, which leads to the imbalance of regional structure of residents' happiness index.

\section{Conclusion and Strategy}

Through the five first-level indicators of residents' income, residents' consumption, residents' living environment, residents' medical conditions, and cultural and educational environment, and 16 second-level indicators, the happiness index of nine cities in the Pearl River Delta of Guangdong Province is calculated. Through empirical research, it is found that the happiness of residents in the Pearl River Delta has the following three characteristics: the regional structure is quite different. Shenzhen and Guangzhou have always ranked first and second in the happiness index, while Jiangmen and Zhaoqing have always been hovering in the last two. Urban groupization, with Shenzhen, Guangzhou, and Zhuhai as the centers, respectively, shows the characteristics of group aggregation. The happiness index of residents in central cities has a siphon effect on surrounding cities. The happiness index of central cities increases year by year, and that of other surrounding cities decreases year by year. The happiness index gap between central cities and surrounding cities increases year by year. According to the research results, the following suggestions are put forward.

First, we should accelerate the integrated development of cities in the Pearl River Delta, actively expand the happiness radiation effect of central cities on surrounding cities, and reduce regional differentiation. Taking Guangzhou and Shenzhen as the center, we should promote regional integration development, realize regional coordinated development, promote the integration development of central cities and surrounding cities, promote unified market construction, integrated and efficient infrastructure, coconstruction and sharing of public services, industrial specialization and division of labor, and coprotection and cogovernance of ecological environment, enhance the comprehensive carrying capacity and radiation leading role of the metropolitan area, comprehensively improve the development quality of the Pearl River Delta urban agglomeration, and reduce regional differences.

Second, we should strengthen the balanced development within the city, focusing on the balanced development between different development indicators. There is a development imbalance in the first-level index system of happiness development level of urban residents in the Pearl River Delta. Shenzhen's residents' income membership ranks first in the Pearl River Delta cities, but its residents' living environment membership ranks first in the reciprocal, indicating Shenzhen's rapid economic development at the same time, the construction of residents' living environment is lagging behind, there is a serious imbalance between different development indicators, there are also imbalances in different development indicators in other cities, and the government should pay attention to the coordinated development of indicators in the planning of urban development, increase financial budget investment in public expenditure, and effectively improve residents' happiness.
Third, we should actively change the mode of growth, while paying attention to economic development, we will continue to pay attention to the investment and improvement of residents' living environment, culture, education, and medical conditions. We should optimize the economic structure, establish the scientific concept of development, take the road of new industrialization and the development of economy at the same time, increase the public finance in the residents' living environment, cultural education, and medical facilities perfect, pay attention to improve people's livelihood, give priority to the development of education, the introduction of powerful policy measures, and the quality of education resources to the surrounding city tilt, and gradually narrow the gap in regional education development. Community as a unit, the construction of ecological livable community, increases the construction of urban green space and improves the living environment of residents.

Fourth, the most fundamental way to improve residents' happiness index is to change the concept of development. We should establish the concept of people-oriented and change the concept of eager for quick success and instant benefit and only paying attention to economic development. We should establish a people-oriented concept, when conducting government assessment, the government should pay more attention to the development of local people's livelihood, rather than only focusing on economic development. We should realize the harmonious development of urban and rural, human, and nature, so as to improve the happiness index of urban and rural residents.

Fifth, we should enhance the comprehensive experience of residents' happiness and comprehensively improve residents' happiness. We should improve the health level of urban and rural people by focusing on "medical treatment," improve the urban and rural social security system by focusing on "supporting the elderly," and improve the development of education and culture around the principle of "learning and education." Focusing on "labor income," we should encourage urban and rural workers to start businesses and find jobs to increase residents' income. We should focus on "housing" to improve the living environment of urban and rural residents.

\section{Data Availability}

The data used to support the findings of this study are available from all the authors upon request.

\section{Conflicts of Interest}

The authors declare there are no conflicts of interest regarding the publication of this paper.

\section{Acknowledgments}

This research was financially supported by the 13th FiveYear Plan for the Development of Philosophy and Social Sciences in Guangzhou in 2020 "Research on the Influence Mechanism of Physical Consumption and Experience Consumption on Happiness of Residents in Guangzhou" 
(grant no. 2020GZGJ210); 2021 Huashang College "SchoolLevel Quality Engineering First-Class Professional Construction of Marketing" (grant no. HS2021ZLGC01); and Key Discipline Construction of Enterprise Management of Guangzhou Huashang University (grant no. 2020HSXK05).

\section{References}

[1] E. Diener, "Subject well-being: the science of happiness and a proposal for a national index," American Psychologist, no. 55, pp. 81-84, 2002.

[2] R. R. Mccrae and P. T. Costa, "Adding Liebe und Arbeit: the Full Five-Factor Model and Well-Being," Personality and Social Psychology, vol. 17, no. 2, pp. 227-232, 1991.

[3] W. R. R. Wilson, "Correlates of avowed happiness," Psychological Bulletin, vol. 67, no. 4, pp. 294-306, 1967.

[4] M. Laura Arrosa and N. Gandelman, "Happiness decomposition: female optimism," Journal of Happiness Studies, vol. 17, no. 2, pp. 731-756, 016.

[5] D. G. See Blanchflower and A. J. Oswald, "Is well-being U-shaped over the life cycle?" Social Science \& Medicine, vol. 66, no. 8, pp. 1733-1749, 2007.

[6] S. Han, H. Kim, and L. Hee-Sun, "A multilevel analysis of the compositional and contextual association of social capital and subjective well-being in seoul, South Korea," Social Indicators Research, vol. 111, no. 1, 2013.

[7] A. Leung, C. Kier, T. Fung, L. Fung, and S. Robert, "Searching for happiness: the importance of social capital," Journal of Happiness Studies, vol. 12, no. 3, 2011.

[8] R. A. Easterlin, "Does economic growth improve the human lot? Some empirical evidence," in Nations and Households in Economic Growth: Essays in Honor of Moses Abramowitz, P. D. M. Reder, Ed., Academic Press, Cambridge, MA, USA, 1974.

[9] J. S. Duesenberry, Income, Saving and the Theory of Consumer Behaviour, pp. 1-12, Harvard University Press, Cambridge, MA, USA, 1952.

[10] H. Zheng and W. Ma, "Click it and buy happiness: does online shopping improve subjective well-being of rural residents in China?" Applied Economics, vol. 53, no. 36, 2021.

[11] J. J. Xiao, C. Yan, P. Bialowolski, and N. Porto, "Consumer debt holding, income and happiness: evidence from China," International Journal of Bank Marketing, vol. 39, no. 5, 2021.

[12] Z. Liu and Li Zhang, "Household debt and happiness: evidence from the China household finance survey," Applied Economics Letters, vol. 27, no. 3, 2020.

[13] Z. Zhu, W. Ma, C. Leng, and N. Peng, "The relationship between happiness and consumption expenditure: evidence from rural China," Applied Research in Quality of Life, 2020.

[14] X. Zheng, Z.-q. Yuan, and X. Zhang, "Does happiness dwell in an owner-occupied house? Homeownership and subjective well-being in urban China," Cities, vol. 96, 2020.

[15] S. Ke and X. Lu, "Real estate investment, loan preference, and national happiness: evidence from China," Land, vol. 10, no. 4 , 2021.

[16] D. Zhao, J. Jiang, and Z. Yin, "Can entrepreneurship bring happiness? Evidence from China," Economic Modelling, p. 91, 2020.

[17] R. Veenhoven, Apparent Quality of Life in Nations: How Long and Happy People live, Quality of Life Research in Chinese,Western and Global Contexts, pp. 61-86, Springer, Berlin, Germany, 2005.
[18] S. Appleton and L. Song, "Life satisfaction in urban China: components and determinants," World Development, vol. 11, 2008.

[19] A. E. Clark, S. Fleche, and C. Senik, "Economic growth evens out happiness: evidence from six surveys," Review of Income and Weslth, no. 3, 2016.

[20] Z. Ouyang, F. Liu, Z. Ge, and B. Svitlana, "Assessment of resident happiness under uncertainty of economic policies: empirical evidences from China," Sustainability, vol. 12, no. $18,2020$.

[21] O.. Sjöberg, "Social insurance as a collective resource: unemployment benefits, job insecurity and subjective well-being in a comparative perspective," Social Forces, vol. 88, no. 3, 2010.

[22] S. Luechinger and P. A. Raschky, "Valuing flood fisasters using the life datisfaction approach," Journal of Public Economics, vol. 93, no. 3-4, pp. 620-633, 2009.

[23] S. Luechinger, "Life satisfaction and transboundary air pollution," Economics Letters, vol. 107, no. 1, pp. 4-6, 2010.

[24] K. Rehdanz and D. Maddison, "Local environment quality and life-satisfaction in Germany," Ecological Economics, vol. 64, no. 4, pp. 787-797, 2008.

[25] C. L. Ambrey and C. M. Fleming, "Valuing scenic amenity using life satisfaction data," Ecological Economics, vol. 72, pp. 106-115, 2011.

[26] B. M. S. van Praag and B. E. Baarsma, "Using happiness surveys to value intangibles: the case of airport noise," The Economic Journal, vol. 115, no. 500, pp. 224-246, 2005.

[27] K. Rehdanz and D. Maddison, "Local environmental quality and life-satisfaction in Germany," Ecological Economics, vol. 64, no. 4, pp. 787-797, 2008.

[28] S. Ferreira and M. Moro, "On the use of subjective well-being data for environmental valuation," Environmental and Resource Economics, vol. 46, no. 3, pp. 249-273, 2010.

[29] K. Katsouyanni, A. Gryparis, and E. Samoli, "Short-term effects of air pollution on health," Encyclopedia of Environmental Health, pp. 51-60, 2011.

[30] W. Guo, L. Chen, Y. Fan, M. Liu, and F. Jiang, "Effect of ambient air quality on subjective well-being among Chinese working adults," Journal of Cleaner Production, p. 296, 2021.

[31] J. Wang, Y. Wang, C. Sun, and X. Chen, "Does mandatory air quality information disclosure raise happiness? Evidence from China," Energy Economics, p. 94, 2021.

[32] Z. Jin, S. Zeng, C. Cao, H. Ma, and D. Sun, "Impacts of pollution abatement projects on happiness: an exploratory study in China," Journal of Cleaner Production, p. 274, 2020.

[33] S. Guo, W. Wang, and M. Zhang, "Exploring the impact of environmental regulations on happiness: new evidence from China," Environmental Science and Pollution Research International, vol. 27, no. 10, pp. 19484-19501, 2020.

[34] Y. Song, A. Zhou, and M. Zhang, "Exploring the effect of subjective air pollution on happiness in China," Environmental Science and Pollution Research International, vol. 27, no. 34, pp. 43299-43311, 2020.

[35] L. Kang, Z. Yang, and F. Han, "The impact of urban recreation environment on residents' happiness-based on a case study in China," Sustainability, vol. 13, no. 10, 2021.

[36] Y. Dang, L. Chen, W. Zhang, D. Zheng, and D. Zhan, "How does growing city size affect residents' happiness in urban China? A case study of the Bohai rim area," Habitat International, vol. 97, 2020. 